\section{THE ARTIFICIAL MENOPAUSE}

\section{WITH PARTICULAR REFERENCE TO THE OCCURRENCE OF SPINAL POROSIS}

\author{
BY
}

IAN A. DONALDSON, F.R.C.S., M.R.C.O.G.

First Assistant in Gynaecology and Obstetrics, .St. George's Hospital, London

AND

\section{J. R. NASSIM, F.R.C.P.}

Physician, St. George's Hospital and the Royal National Orthopaedic Hospital

Many states of ill-health have been attributed to the menopause, and it has been suggested that these manifest themselves more severely if the menopause is produced artificially. In addition to the disorders already recognized there has been added in recent years the occurrence of osteoporosis affecting mainly the spine and pelvis. Thus Albright and Reifenstein (1948) state that " a moderate degree of osteoporosis of the spine is almost physiological after the menopause: its degree increases as the time during which the post-menopausal state has existed increased." This statement implies that one should expect to encounter a larger number of cases of spinal porosis, possibly at an earlier age, in women who have been subjected to an artificial menopause.

It was with the idea of investigating this problem that the present inquiry was instituted, and an opportunity was taken to study other manifestations attributed to the menopause.

In discussing post-menopausal osteoporosis we are adhering to the definition of Albright and his associates presented in a series of recent publications. The term implies a condition in which there is no abnormality in either calcium or phosphorus metabolism, but in which there is a depression of osteoblastic activity, presumably due to hormone imbalance brought about by oestrogen lack; and the serum calcium, phosphorus, and alkaline phosphates are within normal limits, though there is a tendency for the serum phosphate to be slightly higher (Reifenstein, Kinsell, and Albright 1946).

\section{Post-menopausal Osteoporosis : Clinical Investigation}

Two groups of patients formed the basis of this investigation. The first group consisted of 94 women who had been subjected to an artificial menopause either by surgery or by radium at St. George's Hospital at least eighteen months prior to this study. For comparison a second group was studied; this consisted of 28 women who attended hospital because of backache and were found to have spinal porosis. All but two of these patients were seen at the Royal National Orthopaedic Hospital. Both groups were interviewed and clinically examined by one of us (J. R. N.). Particular attention was given to the following points: (1) radiological evidence of osteoporosis, (2) estimation of serum phosphate, (3) dietary history, (4) blood pressure, (5) changes in weight, (6) the incidence of hot flushes, and (7) changes in libido.

Radiological Evidence.-The radiological evidence of the early stages of osteoporosis of the spine is difficult of interpretation, and we were fortunate in having all the films assessed by the same radiologist. For convenience the abnormalities found have been divided into three grades: (1) A marked stencilling of the vertebral bodies with coarsening of bone trabeculation. (2) The above, together with swelling of the intervertebral disks, giving rise to biconcavity and the so-called codfish vertebrae. (3) The above with, in addition, crush fractures.

\section{Group 1}

In the first group of patients follow-up inquiries were sent to 150 , but 56 could not be traced. Of the 94 patients who were interviewed and examined, 82 had had surgical removal of both ovaries and 12 had had the menopause induced by radium. The interval between operation and interview ranged from 18 months to 13 years. The age of the patients at the time of operation varied from 26 to 73 years, but the majority were in the fifth decade (56 patients) and the sixth decade (28 patients). Nineteen were spinsters, and of the remaining 75 who had been married 9 had never been pregnant.

Three of the 82 patients who had had surgical removal of the ovaries failed to have a radiological examination of the spine. Ten $(12.6 \%)$ of the remaining 79 showed radiological evidence of osteoporosis. Only one of them complained of backache. Details of these 10 cases are:

$\begin{array}{lllllllllll}\text { Age at examination } & 49 & 51 & 55 & 56 & 58 & 59 & 61 & 69 & 69 & 76\end{array}$ $\begin{array}{llrrrrrrrrrr}\text { Age at operation } & \ldots & 43 & 48 & 42 & 50 & 55 & 56 & 58 & 67 & 65 & 73 \\ \text { Interval in years } & . . & 6 & 3 & 13 & 6 & 3 & 3 & 3 & 2 & 4 & 3\end{array}$

Only 2 of the 12 patients who had been subjected to a radium menopause showed evidence of osteoporosis. They were aged 59 and 62 at the time of the examination, and 46 and 49 at operation, giving an interval of 13 years in both cases.

Thus of the 94 patients, $12(12.7 \%)$-showed some radiological evidence of osteoporosis, and 3 of them were over 65 at the time of examination. Not one of these 12 patients showed a porosis which was of a greater severity than grade I, which can most certainly be regarded as physiological in the three patients over 65 , and open to argument with regard to the remainder.

The average level of serum phosphate for the group which had undergone surgical menopause was $2.6 \mathrm{mg}$. per $100 \mathrm{ml}$. and for the 12 patients subjected to radium menopause it was $3 \mathrm{mg}$. per $100 \mathrm{ml}$. of serum.

All these patients were asked about their dietary habits, and no information was obtained indicating any marked deviation from normal.

In this series of patients the incidence of osteoporosis can be regarded as within the physiological range, and no significant abnormality in serum phosphate was observed.

\section{Group 2}

The second group, comprising 28 patients, all came to hospital with a specific complaint of pain in the back. Details are shown in Table I. The average age at examina-

TABLE I.-Patients Trealed for Post-menopausal Osteoporosis of Spine

\begin{tabular}{|c|c|c|c|c|c|c|c|c|c|}
\hline \multirow{2}{*}{$\begin{array}{l}\text { Case } \\
\text { No. }\end{array}$} & \multirow{2}{*}{$\begin{array}{c}\text { Duration } \\
\text { of } \\
\text { Backache }\end{array}$} & \multirow{2}{*}{ 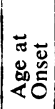 } & \multirow{2}{*}{ 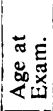 } & \multirow{2}{*}{$\begin{array}{l}\text { Age at } \\
\text { Meno- } \\
\text { pause }\end{array}$} & \multirow{2}{*}{$\begin{array}{c}\text { Years } \\
\text { Between } \\
\text { Menopause } \\
\text { and Exam. }\end{array}$} & \multirow{2}{*}{ 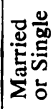 } & \multicolumn{2}{|c|}{ Parity } & \multirow{2}{*}{ 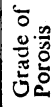 } \\
\hline & & & & & & & C. & Mis. & \\
\hline $\begin{array}{r}1 \\
2 \\
3 \\
4 \\
5 \\
6 \\
7 \\
8 \\
9 \\
10 \\
11 \\
12 \\
13 \\
14 \\
15 \\
16 \\
17 \\
18 \\
19 \\
20 \\
21 \\
22 \\
23 \\
24 \\
25 \\
26 \\
27 \\
28\end{array}$ & 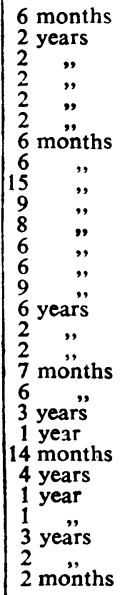 & $\begin{array}{l}43 \\
43 \\
47 \\
49 \\
49 \\
51 \\
53 \\
54 \\
57 \\
57 \\
57 \\
60 \\
62 \\
61 \\
58 \\
62 \\
63 \\
64 \\
65 \\
63 \\
69 \\
69 \\
66 \\
70 \\
71 \\
69 \\
70 \\
73\end{array}$ & $\begin{array}{l}43 \\
45 \\
49 \\
51 \\
51 \\
53 \\
53 \\
54 \\
58 \\
58 \\
58 \\
60 \\
62 \\
62 \\
64 \\
64 \\
65 \\
65 \\
65 \\
66 \\
70 \\
70 \\
70 \\
71 \\
72 \\
72 \\
72 \\
73\end{array}$ & $\begin{array}{l}41(\mathrm{~N}) \\
34(\mathrm{~A}) \\
47(\mathrm{~N}) \\
37(\mathrm{~N}) \\
46(\mathrm{~N}) \\
40(\mathrm{~A}) \\
23(\mathrm{~A}) \\
45(\mathrm{~A}) \\
52(\mathrm{~N}) \\
46(\mathrm{~N}) \\
45(\mathrm{~N}) \\
43(\mathrm{~N}) \\
30(\mathrm{~A}) \\
52(\mathrm{~N}) \\
45(\mathrm{~N}) \\
53(\mathrm{~N}) \\
45(\mathrm{~A}) \\
41(\mathrm{~A}) \\
39(\mathrm{~N}) \\
45(\mathrm{~N}) \\
50(\mathrm{~N}) \\
38(\mathrm{~N}) \\
52(\mathrm{~N}) \\
50(\mathrm{~N}) \\
30(\mathrm{~A}) \\
31(\mathrm{~A}) \\
45(\mathrm{~N}) \\
50(\mathrm{~N})\end{array}$ & $\begin{array}{r}2 \\
11 \\
2 \\
14 \\
5 \\
13 \\
30 \\
9 \\
6 \\
12 \\
13 \\
17 \\
32 \\
10 \\
19 \\
11 \\
20 \\
24 \\
26 \\
21 \\
20 \\
32 \\
18 \\
21 \\
42 \\
41 \\
27 \\
23\end{array}$ & 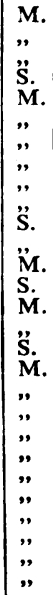 & $\begin{array}{r}0 \\
0 \\
1 \\
0 \\
0 \\
1 \\
0 \\
0 \\
1 . \\
0 \\
0 \\
0 \\
0 \\
0 \\
10 \\
3 \\
0 \\
0 \\
3 \\
1 \\
3 \\
3 \\
0 \\
0 \\
3 \\
1 \\
0 \\
2\end{array}$ & $\begin{array}{l}0 \\
0 \\
0 \\
0 \\
0 \\
0 \\
1 \\
0 \\
1 \\
0 \\
0 \\
0 \\
0 \\
0 \\
0 \\
0 \\
0 \\
0 \\
0 \\
0 \\
0 \\
0 \\
0 \\
0 \\
1 \\
0 \\
0 \\
0\end{array}$ & $\begin{array}{l}3 \\
3 \\
2 \\
3 \\
2 \\
3 \\
3 \\
3 \\
3 \\
2 \\
3 \\
3 \\
2 \\
2 \\
3 \\
3 \\
2 \\
2 \\
2 \\
3 \\
2 \\
3 \\
2 \\
3 \\
3 \\
3 \\
3 \\
3\end{array}$ \\
\hline
\end{tabular}

N. = Natural. A. $=$ Artificial. $\quad$ C. $=$ Number of children. $\quad$ Mis. $=$ Number of miscarriages. 
tion and investigation of these patients was 61.6 years. Their individual ages ranged from 43 to 73 . Nine patients were over 65 , and 15 had had no pregnancies. Of these 28,9 had been subjected to some form of pelvic surgery, with removal of either one or both ovaries. An accurate history of the surgical procedure was impossible to obtain in all cases.

Eighteen of these patients had grade 3 porosis and 10 had grade 2.

Of the 27 patients for whom serum phosphate figures were available the average was $3.6 \mathrm{mg}$. per $100 \mathrm{ml}$. This finding of an increase in the serum phosphate level is in agreement with the observations of Albright, Smith, and Richardson (1941).

The age of these women at the time of the menopause, whether artificial or natural, ranged from 23 to 53 . The ages at the time of operation could be ascertained, but it must be understood that, particularly among the older women, the exact date of the menopause was difficult to obtain, but was probably accurate to within a year or two. The onset of symptoms after the menopause, whether artificial or natural, varied from 2 to 42 years. The average time of onset of symptoms in the 9 patients on whom an operation had been performed was 21.6 years from the time of operation. In the 19 patients on whom no operation was performed the average time of onset of symptoms from the date of their menopause was 15.2 years. We feel that this disparity is due to the small number of cases in this series.

Comment.-Albright, Smith, and Richardson (1941) gave clinical data about 42 patients with spinal osteoporosis, 40 women and 2 men. Because of the possibility of senescence being a factor no patient over the age of 65 was included. Of the 40 women in their series, 10 had been subjected to an artificial menopause. The average time of onset of s! mptoms in these 10 patients following the operation was 13.4 years, whilst in the remaining 27 (three women were excluded because of complicating thyrotoxicosis) the average time was $9 \frac{1}{2}$ years. The difference between these values was not regarded as being statistically significant.

\section{Observations on Blood Pressure}

A blood-pressure reading of over 150/90 was regarded as abnormal. In the first group of 94 patients 28 had a raised blood pressure ; of these, 7 had a high blood pressure recorded prior to operation, and 20 (including 5 of the 7) gave a family history of severe cardiovascular disease in one or other parent. Thus $6(6.3 \%)$ of the 94 patients had an unexplained rise of blood pressure, and the average age was 55.3 years.

\section{Changes in Body Weight}

In the first group of 94 patients, 54 stated that they had gained over $14 \mathrm{lb}$. (6.4 kg.) since the operation, 20 had gained less than $14 \mathrm{lb}$. (6.4 kg.), 20 noted no change in weight, and 5 had lost weight. This confirms the impression that, following an artificial menopause, a gain in weight is to be expected, though it does not invariably occur. In $26.5 \%$ of patients the weight remained unchanged or decreased. Bland-Sutton and Giles (1926) were of the opinion that complete removal of both ovaries "may cause obesity in a woman who has a tendency to form fat." There was a correlation between marked increase in weight and severe hot flushes, and vice versa, in $70 \%$ of patients. Whether there is any significance in this observation is uncertain.

\section{Incidence and Duration of Hot Flushes}

These were studied in the first group of patients. In Table II this series is analysed according to age groups and method of induction of the menopause ; the results of other observers are included for comparison. Approximately $75 \%$ of patients complained of hot flushes after removal of both ovaries; this agrees with the investigations of other
TABLE II.-Incidence and Duration of Hot Flushes. Present and Previously Reported Series

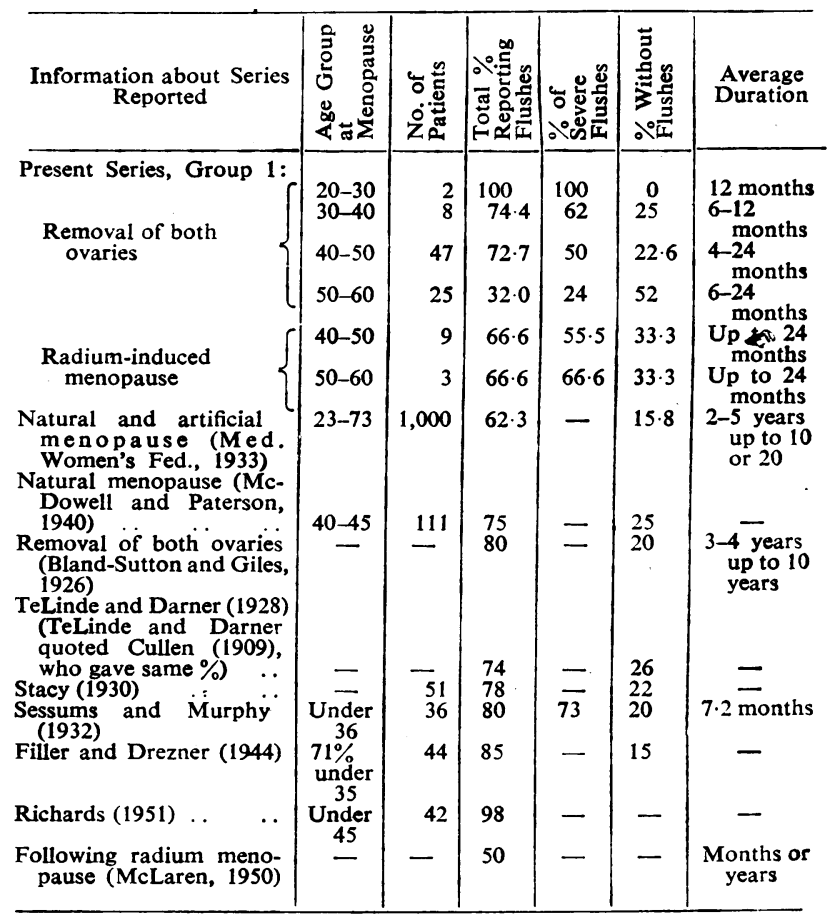

workers. The duration varied between 4 and 24 months. The younger the women were at the time of the menopause the greater was the increase in percentage. In the younger age groups the flushes were more severe, but the total duration tended to be shorter. It has been suggested that the flushes are worse after a radium-induced menopause ; this contention is not supported by this small series, in which $66.6 \%$ developed this symptom. McLaren (1950) stated that $50 \%$ developed hot flushes. The incidence of hot flushes occurring in association with the natural menopause is obtained from two investigations into a larger series of women.

The Council of the Medical Women's Federation (1933) found that $62.3 \%$ of 1,000 women complained of hot flushes. The duration varied from 2 years up to 20 years. McDowell and Paterson (1940) found that $75 \%$ of 111 women between 40 and 45 complained of hot fiushes.

It is interesting to note that about 20 to $25 \%$ of women do not complain of hot flushes after the artificial menopause. The reason for this, like the cause of the hot flush, has yet to be elucidated.

\section{Changes in Libido}

Alteration in libido following removal of the ovaries has long been studied. Battey (1876), writing about the "extirpation of the functionally active ovaries for the remedy of otherwise incurable diseases," was of the opinion that the aphrodisiac propensity was not annulled after the removal of the ovaries. Goodell (1879) was of the opinion that removal of the ovaries does not unsex a woman, and he quoted Koeberle to the same effect.

Interrogation of the married patients in the first group showed that libido was decreased in $65 \%$. These findings are further analysed in Table III with those of other workers for comparison.

A varying percentage of patients have decreased libido following removal of the ovaries; this is to be expected when the host of factors which influence libido are considered. Lewis and Jackson (1940) found that assessment was difficult because so many were frigid before operation.

The percentage tends to be higher in the younger age groups, though Filler and Drezner (1944), who studied 36 negresses in their series of 41 cases, did not confirm this, and 
TABLE III.-Change in Libido Following Artificial Menopause

\begin{tabular}{|c|c|c|c|c|c|}
\hline \multirow[b]{2}{*}{ Series } & \multirow[b]{2}{*}{$\begin{array}{c}\text { Age } \\
\text { Group }\end{array}$} & \multirow[b]{2}{*}{$\begin{array}{l}\text { No. of } \\
\text { Patients }\end{array}$} & \multicolumn{3}{|c|}{ Libido } \\
\hline & & & $\begin{array}{l}\text { De- } \\
\text { creased } \\
(\%)\end{array}$ & $\left|\begin{array}{c}\text { Un- } \\
\text { changed } \\
(\%)\end{array}\right|$ & $\begin{array}{c}\text { In- } \\
\text { creased } \\
(\%)\end{array}$ \\
\hline Present series, Group 1: & & & & & \\
\hline $\begin{array}{l}\text { Removal of both } \\
\text { ovaries }\end{array}$ & $\begin{array}{l}20-30 \\
30-40 \\
40-50 \\
50-60\end{array}$ & $\begin{array}{r}1 \\
5 \\
32 \\
13\end{array}$ & $\begin{array}{l}100 \\
80 \\
62 \cdot 5 \\
61 \cdot 3\end{array}$ & $\begin{array}{l}\overline{20} \\
34 \cdot 3 \\
38 \cdot 7\end{array}$ & $\overline{\overline{3} \cdot 1}$ \\
\hline $\begin{array}{l}\text { Radium-induced } \\
\text { menopause } \\
\text { Removal of both ovaries } \\
\text { (Bland-Sutton and Giles, }\end{array}$ & $\begin{array}{l}40-50 \\
50-60\end{array}$ & $\begin{array}{l}8 \\
1\end{array}$ & $62 \cdot 5$ & 100 & 二 \\
\hline $\begin{array}{l}\text { 1eme } \\
\text { TeLinde and Darner }\end{array}$ & 二 & 52 & $\begin{array}{l}32 \\
40 \cdot 4\end{array}$ & $\begin{array}{l}68 \\
53\end{array}$ & 5 \\
\hline $\begin{array}{l}(1928) \\
\text { Lewis and Jackson (1940) } \\
\text { Filler and Drezner (1944) }\end{array}$ & $\begin{array}{l}20-29 \\
36-55 \\
71 \%\end{array}$ & $\begin{array}{r}6 \\
25 \\
41\end{array}$ & $\begin{array}{l}83 \cdot 3 \\
50 \\
7\end{array}$ & $\frac{16 \cdot 6}{88}$ & $\overline{5}$ \\
\hline Filer and Drezner (1944) & Under 55 & & & & \\
\hline $\begin{array}{lll}\text { Koppen (1948) } & \ldots & \ldots \\
\text { Huffman (1950) } & \ldots & \ldots \\
\text { Richards (1951) } & \ldots & \ldots\end{array}$ & $\begin{array}{c}2 \overline{26-40} \\
\text { Under } 45\end{array}$ & $\begin{array}{l}50 \\
68 \\
33\end{array}$ & $\begin{array}{l}30 \\
10 \cdot 2 \\
60\end{array}$ & $\overline{89 \cdot 7}$ & $\overline{6}$ \\
\hline
\end{tabular}

Huffman (1950), by careful supervision, reported only a small percentage with decreased libido.

In all series there is a significant percentage in which the libido is unchanged after artificial menopause; this stresses the fact that the ovary is not essential for sexual libido and demonstrates the importance of complex factors, including upbringing, education, and marital relationships. BlandSutton and Giles (1926) stated that "facts are accumulating which tend to show that the ovaries are not the seat of the sexual passion... the complete removal of both ovaries is followed in adult women by sterility and persistent amenorrhoea, and these are the only two constant effects attributed to it."

Novak (1948) stated: "In the human being the ovary has very little to do with libido, the sex sense ... . in the human female; the seat of libido is in the psyche with certain auxiliary erogenous zones such as the vagina, the clitoris, and the mammary gland. The ovaries in themselves are not essential at all to sex gratification."

These points have been further studied in pre- and postoperative discussions with patients not included in this series. Reassurance and correction of preconceived and erroneous beliefs has permitted return of libido, and it has been established beyond question that a full orgasm can subsequently be obtained. Adequate briefing should be considered as essential in the management of such patients.

\section{Conclusions}

There was no evidence that osteoporosis of significant degree was precipitated by an artificial menopause, or that, in patients with established osteoporosis, it occurred at an earlier age following an artificial menopause.

The occurrence of post-menopausal osteoporosis is unpredictable ; the time of its onset or severity cannot be related to the age at which the menopause-natural or artificial-occurs, or to the number or frequency of pregnancies. The tendency for the serum phosphate level to be raised in patients with fully developed porosis is confirmed.

There was no evidence that hypertension was attributable to the artificial menopause. The hereditary factor was clearly demonstrated by the high proportion of those hypertensive patients who gave a family history of severe cardiovascular conditions in one or other parent.

An increase in weight occurs in most patients, but there was no increase or even a decrease in weight in $26.5 \%$.

Hot flushes occurred in approximately $75 \%$ of patients. The duration varied between 4 and 24 months. 'The incidence is higher and the duration tends to be shorter in the younger age groups. There was no significant difference between patients who had had a surgical menopause and those with a radium menopause. The incidence and duration are similar to those following the natural menopause in comparable age groups.
After an artificial menopause libido was decreased in approximately $65 \%$ of patients. The façt that the ovary is not essential for the maintenance of the libido is shown by the percentage of patients who were unaffected.

This investigation emphasizes that the only two constant effects of removal of the ovaries are amenorrhoea and sterility.

\section{Summary}

The occurrence of post-menopausal osteoporosis is discussed. The incidence of osteoporosis in 94 patients following artificial menopause is analysed. A group of 28 patients with definite osteoporosis is investigated in relation to the lapse of time after a natural or artificial menopause.

The serum phosphate levels in both groups of patients are given.

The incidence of unexplained raised blood pressure after an artificial menopause is recorded and discussed. The change in weight following artificial menopause is recorded.

The incidence and duration of hot flushes in 94 patients who had an artificial menopause are detailed.

The change in libido in patients after induced menopause is discussed.

We are grateful to the gynaecological staff at St. George's Hospital for allowing us to use their material and to Dr. E. H. Allen for his kindness in assessing the radiological evidence.

\section{REFERENCES}

Albright, F, and Reifenstein, E. C. (1948). The Parathyroid Glands and Metabolic Bone Disease, p. 146. Bailliere, Tindall and Cox, London. Metabolic Bone Disease, p. 146. Baillière, Tindall and Cox, London.
Smith, P. H., and Richardson, A. M. (1941). J. Amer. med. Ass., 116, 2465.

Battey, R. (1876). Trans. Amer. gynec. Soc., 1, 101.

Bland-Sutton, J., and Giles, A. E. (1926). The Diseases of Women. Heinemann, London.

Filler, W., and Drezner, N. (1944). Amer. J. Obstet. Gynec., 47, 122.

Goodell, W. (1879). Boston med. surg. J., 100, 841.

Huffman, J. W. (1950). Amer. J. Obstet. Gynec., 59, 915.

Koppen, K. (1948), Zbl. Gynäk., 70, 570.

Lewis, A. J., and Jackson. J. (1940). J. Neurol. Psychiat., 3, 101.

McDowell, J. G., and Paterson, A. S. (1940). J. Obstet. Gynaec. Brit. Emp., 47, 319.

McLaren, H. C. (1950). British Medical Journal, 2, 76.

Medical Women's Federation (1933). Lancet, 1, 106

Novak, E. (1948). W. Va med. J., 44, 334.

Reifenstein, E. C., Kinsell, L. W., and Albright, F. (1946), Endocrinology. 39, 71

Richards, N. A. (1951). Proc, roy. Soc. Med., 44, 496.

Sessums, J. V., and Murphy, D. P. (1932). Surg. Gynec. Obstet., 55, 728. Stacy, L. J. (1930). Proc. Mayo Clin., 5, 294.

TeLinde, R. W., and Darner, H. L. (1928). J. Amer. med. Ass., 90, 284.

Turning down the $\$ 10,300,000$ recommended by its committee on programme and budget, the Seventh World Health Assembly adopted a regular budget of $\$ 9,500,000$ for 1955 , an increase of $\$ 1,000,000$ over last year's. This decision was taken by a vote of 28 to 24 , with 7 abstentions. The United States proposal for an even smaller budget of $\$ 8,607,000$ was rejected by 35 votes to 21 , with 6 abstentions. The Indian proposal for a budget of $\$ 9,900,000$ did not come to a vote, and the ceiling of $\$ 9,500,000$ adopted by the Health Assembly came from a proposal of the United Kingdom. By unanimous vote the Federation of Rhodesia and Nyasaland, established eight months ago, was admitted to Associate Membership in the World Health Organization. Other W.H.O. Associate Members are Tunisia and Morocco. The Assembly has also recommended that the next Assembly consider methods of assessing only active members for the regular effective budget, and invited those States which have not been actively participating in the work of the organization to resume participation at the earliest date. 